\title{
Pengaruh Pengalaman Auditor, Locus of Control dan Pengetahuan Mendeteksi Kekeliruan terhadap Audit Judgment di BPKP Sumatera Utara
}

\author{
Antonius KAP Simbolon \\ Universitas Prima Indonesia \\ Medan \\ antoniussimbolon8@gmail.com \\ Jitro Sebayang \\ Universitas Prima Indonesia \\ Medan \\ jitrosebayang96@gmail.com
}

\author{
Ruth Anggie Panjaitan \\ Universitas Prima Indonesia \\ Medan \\ anggie.ruth@yahoo.co.id \\ Chintya Tarihoran \\ Universitas Prima Indonesia \\ Medan \\ chintyatarihoran22@gmail.com
}

\author{
Monica Lb Tobing \\ Universitas Prima Indonesia \\ Medan \\ monicatbng@gmail.com
}

\begin{abstract}
ABSTRAK
The purpose of this research is to examinethe effect of auditor's experience, locus of control and knowledge to detect mistakes positive effect on audit judgment. This research was conducted at BPKP Sumatera Utara province with the primary data collection method is using questionnaire data. The samples used are 95 people is calculated using the formula slovin. Data have valid and reliable, meet the classic assumption test. Analysis technique used is Multiple Linear Regression Analysis with software SPSS. The results of research showed that auditor's experience, locus of control and knowledge to detect mistakes have a significant possitive effect on audit simultan and partial judgment
\end{abstract}

Keywords : Auditor's Experience, Locus Of Control, Knowledge to Detect Mistakes, Audit Judgment

\begin{abstract}
ABSTRAK
Penelitian ini bertujuan untuk mengetahui pengaruh pengalaman auditor, locus of control dan pengetahuan mendeteksi kekeliruan terhadap audit judgment. Penelitian ini dilakukan pada Kantor BPKP Perwakilan Sumatera Utara dengan metode pengumpulan data primer yaitu menggunakan data kuisioner. Jumlah sampel yang digunakan adalah 95 orang yang dihitung menggunakan rumus slovin. Data telah valid dan reliabel, memenuhi uji asumsi klasik. Teknik analisis yang digunakan adalah Analisis Regresi Linear Berganda dengan software SPSS. Hasil penelitian
\end{abstract}


ini menujukkan bahwa pengalaman auditor, locus of control dan pengetahuan mendeteksi kekeliruan mempunyai pengaruh signifikan positif secara simultan dan parsial terhadap audit judgment.

Kata Kunci: Pengalaman Auditor, Locus of Control, Pengetahuan Mendeteksi Kekeliruan, Audit Judgment

\section{PENDAHULUAN}

Badan Pengawas Keuangan dan Pembangunan (BPKP), adalah lembaga pemerintah non kementerian Indonesia yang melaksanakan tugas pemerintahan dibidang pengawasan keuangan dan pembangunan berupa audit, konsultasi, asistensi, evaluasi, pemberantasan korupsi kolusi dan nepotisme (KKN) serta pendidikan dan pelatihan pengawasan sesuai peraturan yang berlaku.

Dalam menjalankan tugas dan fungsinya, Badan Pengawas Keuangan dan Pembangunan (BPKP) memerlukan kinerja auditor yang baik dan berkualitas. Kinerja seorang auditor seringkali digunakan dalam menyebutkan prestasi atau tingkat keberhasilan individu atau kelompok individu. Auditor mendapatkan penghasilan dari organisasi dimana dia bekerja, hal ini berarti auditor sangatlah bergantung pada organisasinya sebagai pemberi kerja. Disini konflik audit muncul ketika auditor menjalankan aktivitas auditing.

Salah satunya kasus yang dikutip dari Kompas.com, mengenai PT. Indosat dan anak usahanya yaitu IM2. Kasus ini terkait laporan audit Badan Pengawan Keuangan dan Pembangunan (BPKP) yang menyatakan adanya kerugian negara $\mathrm{Rp}$ 1,3 triliun dalam pembangunan jaringan frekuensi radio oleh Indosat dan IM2. Majelis hakim menyatakan, audit kerugian negara oleh BPKP dalam kasus ini tidak sah. Karena, audit tidak diawali permintaan dari Kementrian Komunikasi dan Informatika (Kemenkominfo), tidak ditemukannya penggunaan frekuensi bersama Indosat sesuai fakta persidangan dan BPKP tidak pernah melakukan pemeriksaan terhadap PT Indosat dan IM2. Maka dari itu majelis hakim menyatakan surat dari BPKP tentang laporan hasil audit perhitungan negara tidak sah dan cacat hukum. (https://ekonomi.kompas.com)

Dari contoh kasus diatas terlihat bahwa terjadinya kasus gagal audit yang mana auditor dari BPKP telah melakukan kesalahan dalam pengauditan dan juga tidak adanya izin dari Kementrian Komunikasi dan Informatika sehingga menyebabkan adanya tuntuhan hukum dari pihak IM2. Untuk mencegah terjadinya kasus kegagalan audit, auditor dituntut untuk bersikap profesional yang mana telah menjadi isu yang kritis untuk profesi akuntan karena dapat menggambarkan kinerja akuntan yang dapat dicerminkan oleh ketepatan auditor dalam membuat judgement dalam penugasan auditnya (Putri, 2015).

Penelitian ini penting dilakukan karena semakin meningkatnya tuntutan pengguna laporan keuangan terhadap hasil pertimbangan audit (audit judgment) untuk mendapatkan 
laporan audit yang berkualitas. Selain itu, penelitian ini juga penting bagi kantor BPKP untuk menekankan pada semua auditor untuk bekerja professional dengan memberikan prioritas yang tinggi dalam evaluasi kinerja, kompensasi, promosi, dan keputusan untuk mempertahankan pegawai.

\section{KAJIAN PUSTAKA}

Audit judgment dapat dipengaruhi oleh beberapa faktor, yaitu pengalaman auditor, locus of control dan pengetahuan mendeteksi kekeliruan.

Menurut Siagian (2014:2), judgment (pertimbangan) merupakan sebuah proses mengevaluasi fakta dan keadaan, dan menformulasikannya dalaam pendapat apakah itu wajar, hanya, akurat, material atau cukup.

Drupadi dan Sudana (2015:623), audit judgment merupakan suatu pertimbangan atas persepsi dalam menanggapi informasi laporan keuangan yang diperoleh, ditambah dengan faktor-faktor dari dalam diri seorang auditor, sehingga menghasilkan suatu dasar penilaian dari auditor.

Syaravina (2015:5), pengalaman auditor adalah pengalaman dalam melakukan audit laporan keuangan baik dari segi lamanya waktu, banyaknya penugasan, maupun jenisjenis perusahaan yang pernah ditangani.

Roeckelein (2013:532), locus of control terdiri dari dua yaitu locus of control internal dan locus of control external. Bagi individu yang memiliki skor tinggi pada locus of control internal berharap bahwa hasil atau penguat tergantung pada usaha individu sendiri, sementara individu dengan skor tinggi locus of control external mempunyai pengharapan bahwa hasil tergantung pada keberuntungan, kesempatan, nasib, atau faktor eksternal lain; individu dengan locus of control external relatif merasa tidak berdaya dalam peristiwa.

Natalisa dan Bangun (2017:83) dalam Kamus Besar Bahasa Indonesia, defenisi dari pengetahuan adalah segala sesuatu yang diketahui. Mendeteksi adalah melacak, menemukan atau menentukan suatu kenyataan dan kekeliruan adalah kesalahan. Sehingga, pengetahuan mendeteksi kekeliruan adalah suatu kepandaian untuk mampu melacak ataupun menetukan keberadaan suatu kesalahan dalam laporan keuangan.

\section{METODE PENELITIAN}

Pendekatan yang digunakan dalam penelitian ini adalah dengan menggunakan metode kuantitatif. Menurut Sugiyono (2017:7) metode penelitian kuantitatif adalah metode penelitian yang berlandaskan pada filasafat postpositivisme. Metode ini sebagai metode ilmiah karena telah memenuhi kaidah-kaidah ilmiah yaitu konkrit/empiris, obyektif, terukur, rasional, dan sistematis.

Jenis penelitian yang digunakan dalam penelitian ini adalah penelitian untuk mengumpulkan informasi dengan cara menyusun daftar pertanyaan atau pertanyaan yang diajukan kepada responden. Menurut Sugiyono (2017:6), metode survey digunakan untuk mendapatkan data dari tempat tertentu yang alamiah (buatan), tetapi peneliti melakukan 
perlakuan dalam pengumpulan data, misalnya dengan mengedarkan kuesioner, test, wawancara terstruktur dan sebagainya (perlakuan tidak seperti dalam eksperimen).

Sifat penelitian dalam penelitian ini adalah bersifat sebab akibat (kausalitas). Menurut Sugiyono (2017:37), Penelitian kausalitas adalah hubungan variabel terhadap obyek yang diteliti lebih bersifat sebab dan akibat (kausal), sehingga dalam penelitiannya ada variabel independen dan dependen.

Penelitian ini dilakukan di Badan Pengawasan Keuangan dan Pembangunan (BPKP) Perwakilan Sumatera Utara. Populasi dalam penelitian ini adalah seluruh auditor BPKP Perwakilan Sumatera Utara. Jumlah populasi secara keseluruhan adalah 126 orang auditor. Jumlah sampel yang diambil ditentukan dengan menggunakan rumus Slovin yaitu sebanyak 95 orang.

Teknik pengumpulan data dalam penelitian ini adalah dengan menggunakan kuesioner. Kuesioner dikirim secara langsung kepada para responden dengan harapan agar tingkat pengembalian kuesioner tinggi.

Menurut Sugiyono (2017:137) jenis data adalah segala sesuatu yang dapat memberikan informasi mengenai data. Berdasarkan jenisnya, data dibedakan menjadi dua,data primer dan data sekunder. Pada penelitian ini menggunakan data primer. Data primer adalah sumber data yang langsung memberikan data kepada pengumpul data.

Metode analisis data yang digunakan dalam penelitian ini diantaranya adalah analisis statistik deskriptif, uji asumsi klasik yaitu uji Multikolinearitas, uji heterokedasitas, dan uji autokorelasi, analsisis regresi berganda, dan koefisisen determinasi dengan menggunakan bantuan SPSS.

\section{Kerangka Konseptual}

Kerangka Konseptual dalam penelitian ini dapat digambarkan sebagai berikut :

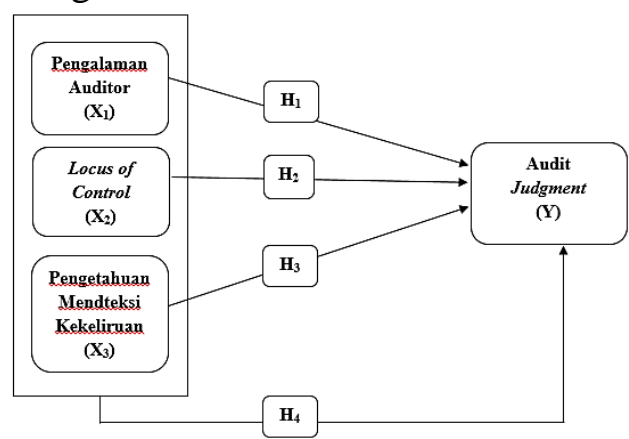

Gambar 1. Kerangka Konseptual Sumber : Hasil Olahan Peneliti (2019)

Berdasarkan kerangka konseptual di atas, maka dapat disusun hipotesis penelitian sebagai berikut :

H1: Pengalaman Auditor secara parsial berpengaruh terhadap Audit Judgment di Kantor BPKP Perwakilan Sumatera Utara.

$\mathrm{H} 2$ Locus of Control secara parsial berpengaruh terhadap Audit Judgment di Kantor BPKP Perwakilan Sumatera Utara.

H3 Pengetahuan Mendeteksi Kekeliruan secara parsial berpengaruh terhadap Audit Judgment di Kantor BPKP Perwakilan Sumatera Utara.

H4 Pengalaman Auditor, Locus of Control, dan Pengetahuan 
Mendeteksi Kekeliruan secara simultan berpengaruh terhadap Audit Judgment di Kantor BPKP Perwakilan Sumatera Utara.

\section{HASIL DAN PEMBAHASAN}

\section{Statistik Deskriptif}

Sampel pada penelitian ini adalah auditor pada Badan Pengawasan Keuangan dan Pembangunan Perwakilan Sumatera Utara yang berjumlah 70 orang jawaban responden yang memenuhi kriteria untuk dilakukan pengolahan data. Statistik deskriptif variabel penelitian dapat dilihat pada tabel berikut:

Tabel 1. Statistik Deskriptif Descriptive Statistics

\begin{tabular}{l|r|r|r|r|r|r|r} 
& N & Range & Minimum & Maximum & Mean & Std. Deviation \\
\hline PENGALAMAN AUDITOR & 95 & 14 & 36 & 50 & 42,52 & 3,467 \\
\hline LOCUS OF CONTROL & 95 & 9 & 31 & 40 & 36,21 & 2,964 \\
\hline PENGETAHUAN M.K & 95 & 9 & 28 & 37 & 31,49 & 1,617 \\
\hline AUDIT JUDGMENT & 95 & 6 & 24 & 30 & 27,87 & 1,886 \\
\hline Valid N (listwise) & 95 & & & & & \\
\hline
\end{tabular}

Sumber : Hasil Olahan Peneliti (2019)

\section{Hasil Uji Asumsi Klasik Uji Normalitas}

Uji normalitas bertujuan untuk menguji apakah dalam model regresi, variabel pengganggu atau residual memiliki distribusi normal. Hasil uji normalitas dapat berupa tabel statistik Kolmogorov Smirnov. Dalam uji ini, pedoman yang digunakan dalam pengambilan keputusan adalah :

1. Jika nilai signifikan lebih besar dari 0,05 maka distribusi normal.

2. Jika nilai signifikan lebih kecil dari 0,05 maka distribusi tidak normal.

Hasil dari pengujian normalitas menggunakan tabel statistik Kolmogorov Smirnov pada penelitian ini adalah sebagai berikut :

Tabel 2. Uji Normalitas dengan Kolmogrov Smirnov

One-Sample Kolmogorov-Smirnov Test

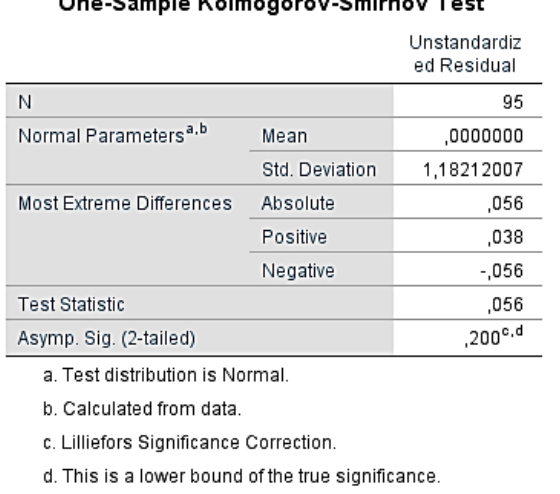

Sumber : Hasil Olahan Peneliti (2019)

Hasil uji statistik normalitas Kolmogorov Smirnov dalam penelitian ini menunjukkan nilai signifikan 0,20 $>0,05$ dengan demikian dapat diambil kesimpulan bahwa dalam hasil uji statistik normalitas Kolmogorov Smirnov data berdistribusi normal.

\section{Uji Multikolinearitas}

Uji multikolinearitas bertujuan untuk menguji apakah pada model regresi ditemukan adanya korelasi antar variabel independen. Pada model regresi yang baik seharusnya tidak terjadi korelasi antar variabel independen. Dalam pengujian multikolinearitas dapat dilakukan dengan melihat Variance Inflation Factor (VIP) antar variabel independen. Nilai cutoff yang umum digunakan untuk menunjukkan adanya multikolinearitas adalah

1. Nilai tolerance $\leq 0.10$ atau,

2. Nilai VIP $\geq 10$.

Hasil Pengujian multikolinearitas yang digunakan dalam penelitian ini dapat dilihat pada tabel berikut : 


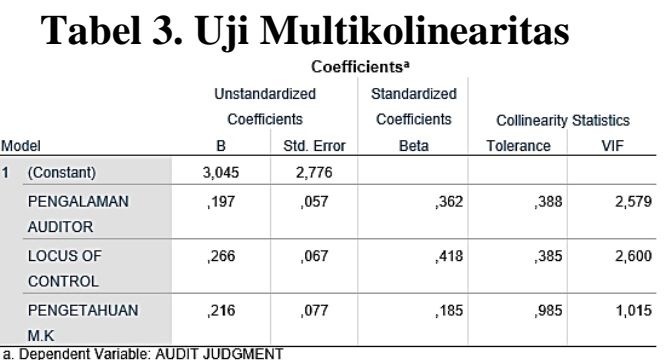

Sumber : Hasil Olahan Peneliti (2019)

Berdasarkan pengujian multikolinearitas pada tabel di atas, model regresi tidak terjadi korelasi antar independen karena nilai tolerance variabel pengalaman auditor, locus of control dan pengetahuan mendeteksi kekeliruan berada di atas 0,10 sedangkan nilai VIF variabel pengalaman auditor, locus of control dan pengetahuan mendeteksi kekeliruan berada di bawah 10 .

\section{Uji Heterokedastisitas}

Uji Heteroskedastisitas berguna untuk menguji apakah dalam model regresi terjadi ketidaksamaan varian dari residual satu pengamatan ke pengamatan yang lain. Pendeteksian ada tidaknya heteroskedastisitas dalam penelitian ini menggunakan Uji glejser.

Jika variabel independen signifikan secara statistik mempengaruhi variabel dependen, maka ada indikasi terjadi heteroskedastisitas. Hasil Pengujian Heterokedastisitas yang digunakan dalam penelitian ini dapat dilihat pada tabel berikut:

Tabel 4. Uji Heterokedatisitas dengan Uji Glejser

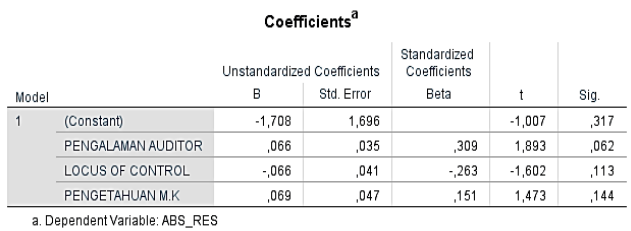

Sumber : Hasil Olahan Peneliti (2019)

Pengujian Heterokedastisitas pada model regresi diatas tidak menunjukkan gejala terjadi heterokedastisitas karena nilai signifikasi variabel pengalaman auditor, locus of control dan pengetahuan mendeteksi kekeliruan berada di atas 0,05.

\section{Hasil Analisis Data Penelitian}

\section{Model Penelitian}

Pengujian hipotesis yang digunakan dalam penelitian adalah dengan menggunakan analisis regresi linier berganda.

Tabel 5. Model Penelitian

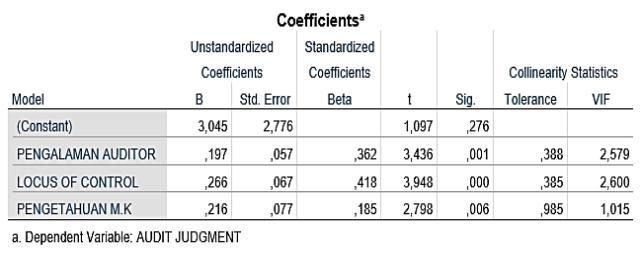

Sumber : Hasil Olahan Peneliti (2019)

Model regresi yang digunakan adalah sebagai berikut :

$$
=\mathrm{a}+\mathrm{b}_{1} X_{1}+\mathrm{b}_{2} X_{2}+\mathrm{b}_{3} X_{3}+e
$$

$Y=3,045+0,197 X_{1}+0,266 X_{2}$ $+0,216 X_{3}$

Dari hasil pengujian regresi diatas, maka dapat dijelaskan sebagai berikut:

1. Konstanta (a) $=3,045$ artinya walaupun variabel bebas (X1) 
yaitu pengalaman auditor dengan nilai 0,197 , variabel bebas (X2) yaitu locus of control dengan nilai 0,266, dan variabel bebas (X3) yaitu pengetahuan mendeteksi kekeliruan dengan nilai 0,216 maka audit judgment (Y) pada Kantor BPKP Perwakilan adalah sebesar 3,045 satuan.

2. Variabel Pengalaman Auditor memiliki hubungan positif terhadap Audit Judgment dimana setiap kenaikan satu satuan variabel pengalaman auditor akan meningkatkan audit judgment sebesar 0,197 satuan.

3. Variabel Locus of Control memiliki hubungan positif terhadap Audit Judgment dimana setiap kenaikan satu satuan variabel locus of control akan meningkatkan audit judgment sebesar 0,266 satuan.

4. Variabel Pengetahuan Mendeteksi Kekeliruan memiliki hubungan positif terhadap Audit Judgment dimana setiap kenaikan satu satuan variabel pengetahuan mendeteksi kekeliruan akan meningkatkan audit judgment sebesar 0,216 satuan.

\section{Koefisien Determinasi Hipotesis}

Koefisien determinasi ditujukan untuk mengetahui seberapa besar kemampuan model dalam menerangkan variabel terikat. Jika koefisien determinasi (R2) semakin besar atau mendekati 1, maka dapat dikatakan bahwa kemampuan variabel bebas (X) adalah besar terhadap variabel terikat $(\mathrm{Y})$.

Berikut hasil koefisien determinasi hipotesis pada penelitian ini :
Tabel 6. Koefision Determinasi Hipotesis

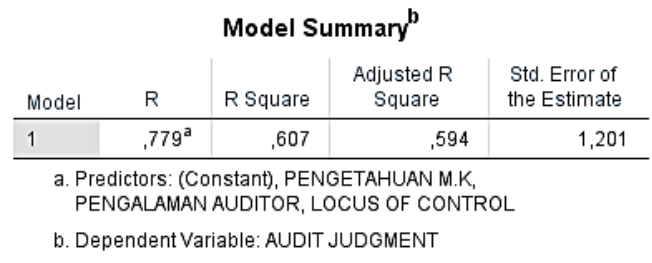

Sumber : Hasil Olahan Peneliti (2019)

Hasil analisis diperoleh bahwa nilai koefisien determinasi hipotesis adalah 0,594 hal ini berarti $59,4 \%$ variasi variabel audit judgment (Y) dapat dijelaskan oleh variabel pengalaman auditor (X1), locus of control (X2), dan pengetahuan mendeteksi kekeliruan (X3). Sisanya 40,6\% merupakan variabel lain yang tidak diteliti dalam penelitian ini.

\section{Uji F (Pengujian Hipotesis Secara Simultan)}

Uji $F$ digunakan untuk menunjukkan apakah semua variabel independen yang dimasukkan dalam model mempunyai pengaruh secara bersama-sama terhadap variabel dependen. Untuk menguji hipotesis ini digunakan statistik $F$ dengan keputusan sebagai berikut:

1. Jika $\mathrm{F}$ hitung $>\mathrm{F}$ tabel atau sig < 0,05, maka H0 ditolak dan $\mathrm{Ha}$ diterima

2. $\quad$ Jika Ftabel $\leq$ Fhitung, atau sig $\geq$ 0,05, maka Ha ditolak dan $\mathrm{H} 0$ diterima

Tabel 7. Uji F 


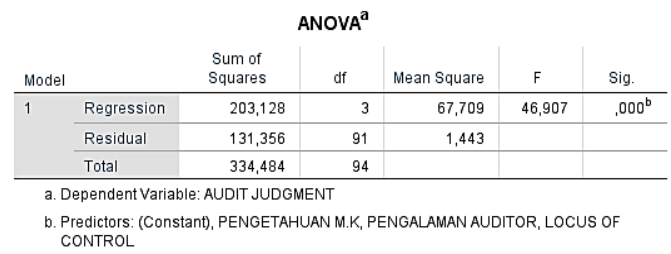

\section{Sumber : Hasil Olahan Peneliti (2019)}

Berdasarkan hasil uji ANOVA, diperoleh nilai $F_{\text {hitung }}$ sebesar 46,907 dimana nilai $F_{\text {hitung }}>F_{\text {tabel }}(46,907$ $>2,70)$ dengan nilai signifikan 0,000 lebih kecil dari $\alpha=0,05$. Hasil penelitian menunjukkan bahwa $H_{a}$ diterima dan $H_{O}$ ditolak yang berarti pengalaman auditor, locus of control dan pengetahuan mendeteksi kekeliruan secara simultan berpengaruh signifikan terhadap audit judgment pada Kantor BPKP Perwakilan Sumatera Utara.

\section{Uji t}

untuk menunjukkan seberapa jauh pengaruh satu variabel independen terhadap variabel dependen. Uji ini dilakukan dengan membandingkan nilai signifikasi dengan ketentuan sebagai berikut :

1. Jika $-\mathrm{t}$ tabel $\leq \mathrm{t}$ hitung $\leq \mathrm{t}$ tabel atau Sig $\geq \alpha=0,05$, maka $\mathrm{Ha}$ ditolak dan $\mathrm{HO}$ diterima.

2. Jika $\mathrm{t}$ hitung $>\mathrm{t}$ tabel atau $-\mathrm{t}$ hitung $\leq-\mathrm{t}$ tabel atau Sig $\geq \alpha=$ 0,05, maka H0 ditolak dan Ha diterima.

\section{Tabel 8. Uji t}

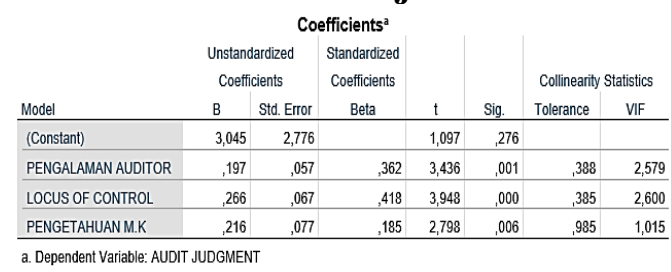

Sumber : Hasil Olahan Peneliti (2019)

Berdasarkan hasil penelitian, diperoleh bahwa:

1. Nilai $t_{\text {hitung }}$ variabel

pengalaman auditor (X1)

sebesar 3,436 dimana nilai

$t_{\text {hitung }}>\quad t_{\text {tabel }}$ yaitu $3,436>$

1,98638 dengan nilai signifikan

0,001 lebih kecil dari 0,05. Hasil

penelitian ini menunjukkan

bahwa $H_{a}$ diterima dan $H_{o}$ ditolak yang berarti pengalaman auditor berpengaruh positif dan signifikan terhadap audit judgment pada Kantor BPKP Perwakilan Sumatera Utara.

2. Nilai $\boldsymbol{t}_{\text {hitung }}$ variabel locus of control (X2) sebesar 3,948 dimana nilai $t_{\text {hitung }}>t_{\text {tabel }}$ yaitu $3,948>1,98638$ dengan nilai signifikan 0,000 lebih kecil dari 0,05. Hasil penelitian ini menunjukkan bahwa $H_{a}$ diterima dan $H_{o}$ ditolak yang berarti locus of control berpengaruh positif dan signifikan terhadap audit judgment pada Kantor BPKP Perwakilan Sumatera Utara.

3. Nilai $t_{\text {hitung }}$ variabel pengetahuan mendeteksi kekeliruan (X3) sebesar 2,798 dimana nilai $t_{\text {hitung }}<t_{\text {tabel }}$ yaitu $2,798<1,98638$ dengan nilai signifikan 0,006 lebih kecil dari 0,05. Hasil penelitian ini menunjukkan bahwa $H_{a}$ diterima dan $H_{o}$ ditolak yang berarti pengetahuan mendeteksi kekeliruan berpengaruh positif dan signifikan terhadap audit 
judgment pada Kantor BPKP Perwakilan Sumatera Utara.

\section{PENUTUP}

\section{Kesimpulan}

Kesimpulan dari hasil penelitian ini adalah:

1. Pengujian hasil secara parsial menunjukkan bahwa pengalaman auditor berpengaruh signifikan terhadap audit judgment di BPKP Perwakilan Sumatera Utara.

2. Pengujian hasil secara parsial menunjukkan bahwa locus of control berpengaruh signifikan terhadap audit judgment di BPKP Perwakilan Sumatera Utara.

3. Pengujian hasil secara parsial menunjukkan bahwa pengetahuan mendeteksi kekeliruan berpengaruh signifikan terhadap audit judgment di BPKP Perwakilan Sumatera Utara.

4. Hasil penelitian membuktikan secara bersama-sama variabel bebas yang terdiri dari pengalaman auditor, locus of control dan pengetahuan mendeteksi kekeliruan berpengaruh signifikan baik secara uji $\mathrm{F}$ dimana nilai $F_{\text {hitung }}$ lebih besar dari $\mathrm{F}_{\text {tabel }}$ dengan besar koefisien determinasi sebesar $59,4 \%$ diperoleh dari $\mathrm{R}$ square sebesar 0,594. Artinya sebesar $59,4 \%$ variasi varibel audit judgment dapat dijelaskan oleh pengalaman auditor, locus of control dan pengetahuan mendeteksi kekeliruan dan sisanya 40,6\% yang tidak diteliti pada penelitian ini seperti kompetensi, profesionalisme, etika profesi dan keahlian auditor dan nilai signifikansi terhadap audit judgment di BPKP Perwakilan Sumatera Utara.

\section{Saran}

Adapun saran dari hasil penelitian ini adalah:

1. Bagi Peneliti

Disarankan untuk menambah referensi dan wawasan serta untuk memperluas pengetahuan mengenai audit judgment agar kelak dapat digunakan dan diterapkan di dunia karir.

2. Bagi Badan Pengawasan Keuangan dan Pembangunan

Dalam melaksanakan audit harus bersikap profesional, tanggung jawab, dan penuh kesungguhan agar auditor dapat menghasilkan audit yang berkualitas dengan hasil yang maksimal.

3. Bagi Universitas Prima Indonesia Hasil penelitian ini dapat memberikan kontribusi pengembangan literatur dan menjadi bahan referensi untuk peneliti berikutnya.

4. Bagi Peneliti Selanjutnya

Diharapkan dapat mempertimbangkan variabel lain yang dapat mempengaruhi audit judgment serta menambah jumlah sampel agar generalisasi hasil penelitian dapat tercapai.

DAFTAR PUSTAKA

Ahyani, Nisma dkk. 2015. Pengaruh Locus of Control, Kompetensi dan Kompleksitas Tugas 
Terhadap Audit Judgment (Studi Empiris Pada Auditor Eksternal Pada KAP Wilayah Jakarta). JSAI Vol.2 No.1.

Christanti, Made Puspita dan AANB

Dwirandra. 2017. Pengaruh Pengalaman Auditor, Locus of Control dan Pengetahuan Mendeteksi Kekeliruan Terhadap Audit Judgment. EJurnal Universitas Akuntansi Vol.18.1.

Udayana

Drupadi, Made Julia dan I Putu Sudana. 2016. Pengaruh Keahlian Auditor, Tekanan Ketaatan dan Independensi Pada Audit Judgment. EJurnal Akuntansi Universitas Udayana Vol.12.3.

Herawaty, Arleen dan Yulius Kurnia. (2009). Pengaruh

Profesionalisme, Pengetahuan Mendeteksi Kekeliruan dan Etika Profesi Terhadap Pertimbangan Tingkat Materialitas Akuntan Publik. Jurnal Ekonomi Fakultas Trisakti.

Hidayatunissa, Indriarta. 2018. Pengaruh Gender, Pengalaman Auditor, Kompleksitas Tugas, Keahlian Auditor dan Tekanan Ketaatan Terhadap Audit Judgment (Studi Empiris pada Perwakilan BPKP Provinsi Riau). JOM FEB, Vol 1 Edisi 1 (Januari-Juni 2018).
Imam, Ghozali.2016. Aplikasi Analisis Multivariete Dengan Program IBM SPSS 23. Semarang: UNDIP.

Natalisa, Desy dan Primsa Bangun. (2017). Pengaruh Profesionalisme, Pengetahuan Mendeteksi Kekeliruan dan Pengalaman Auditor Terhadap Pertimbangan Tingkat Materialitas Dalam Audit Laporan Keuangan. Jurnal Akuntansi Universitas Tarumanegara.

Oktaviana, Made Ayu dan Maria Ratna Sari. 2018. Pengaruh Pengalaman Audit, Pengetahuan Mendeteksi Kekeliruan, Independensi dan Audit Tenure Pada Audit Judgment. E-Jurnal Akuntansi Universitas Udayana Vol.23.3.

Putri, Febrina Prima. (2015). Pengaruh Pengetahuan Auditor, Pengalaman Auditor, Kompleksitas Tugas, Locus Of Control dan Tekanan Ketaatan Terhadap Audit Judgment. Jurnal Fakultas Ekonomi Universitas Riau Vol. 2 Oktober.

Roeckeleim, Jon E. 2013. Kamus Psikologi Teori, Hukum dan Konsep. Kencana. Jakarta.

Sari, Dessy Indah dan Endang Ruhiyat. 2017. Pengaruh Locus of Control, Tekanan Ketaatan dan Kompleksitas Tugas Terhadap Audit 
Judgment. Jurnal Akuntansi Riset Vol. 4, No. 1.

Siagian, Rida MM. 2014. Faktorfaktor yang berpengaruh terhadap audit judgment (studi empiris pada BPK RI perwakilan provinsi Riau). Jurnal Ekonomi Universitas Riau Vol.1, No. 3.

Sugiyono.2017. Metode Penelitian Kuantitatif, Kualitatif, dan $\boldsymbol{R} \& \boldsymbol{D}$. Cetakan Ke-25. Bandung: Alfabeta.

Syaravina. (2015). Pengaruh Professionalisme, Etika Profesi, Pengalaman Auditor dan Independensi Terhadap Pertimbangan Tingkat Materialitas. Jurnal Fakultas Ekonomi Universitas Riau.

(https://ekonomi.kompas.com) 